\title{
Galileo and Huygens on free fall: Mathematical and methodological ifferences
}

\section{Steffen Ducheyne}

Centre for Logic and Philosophy of Science and the Centre for History of Science, Ghent University. Steffen.Ducheyne@UGent.be

Dynamis

[0211-9536] 2008; 28: 243-274
Fecha de recepción: 23 de mayo de 2007

Fecha de aceptación: 15 de noviembre de 2007

SUMMARY: 1.-Introduction. 2.-Galileo's treatment of free all. 3.-Huygens's treatment of free fall. 4.-Comparing Galileo and Huygens.

ABSTRACT: In this essay, I will scrutinize the differences between Galileo's and Huygens's demonstrations of free fall, which can be found respectively in the Discorsi and the Horologium, from a mathematical, representational and methodological perspective. I argue that more can be learnt from such an analysis than the thesis that Huygens re-styled Galilean mechanics which is a communis opinio. I shall argue that the differences in their approach on free fall highlight a significantly different mathematical and methodological outlook.

PALABRAS CLAVE: Huygens, Galileo, caida libre, mecánica, filosofía natural del siglo XVII, Horologium Oscillatorium, Discorsi.

KEYWORDS: Huygens, Galileo, free fall, mechanics, XVIlth century natural philosophy, Horologium Oscillatorium, Discorsi.

\section{Introduction}

In this essay, I shall explore the main mathematical and methodological differences between Galileo's and Huygens's treatment of free fall. It is my aim to clarify and compare the method(ology) employed by Galileo and Huygens in dealing with free fall. When I use «method(ology)» here, I intend to refer to the ways in which scientific statements are demonstrated in a published text - such strategies will typically include mathematical and representational techniques. I do not touch upon the methodology followed during the process of discovery of scientific statements. Needless to say, the context of justification does not necessarily follow the context of discovery. 
Correspondingly, I shall focus on both Galileo's and Huygens's published results on free fall: Discorsi e dimonstrazione matematiche intorno a duo nuove scienze (1638) and Horologium oscillatorium seu de motu pendulorum ad horologia aptato demonstrationes geometricae (1673), respectively. The following propositions (demonstranda) will be studied - I indicate their occurrence in both Galileo's and Huygens's principal work on free fall:

\begin{tabular}{|c|c|c|}
\hline Demonstrandum & $\begin{array}{c}\text { Galileo's } 3^{\text {rd }} \text { day of the } \\
\text { Discorsi }\end{array}$ & $\begin{array}{c}\text { Huygens's } 2^{\text {nd }} \text { part of the Ho- } \\
\text { rologium }\end{array}$ \\
\hline Accelerated motion & $\begin{array}{l}\text { Galileo's definition of } \\
\text { accelerated motion }\end{array}$ & Proposition I \\
\hline Mean-speed theorem & Proposition I & Proposition II + Proposition V \\
\hline Times-squared rule & Proposition II & Proposition III \\
\hline Odd-number rule & $\begin{array}{l}\text { Corollary I to } \\
\text { Proposition I }\end{array}$ & Proposition IV \\
\hline $\begin{array}{l}\text { Equal-height-equal } \\
\text { Velocity theorem }\end{array}$ & Scholium & Proposition VI \\
\hline $\begin{array}{l}\text { Time-length proportion- } \\
\text { Ality for motion along } \\
\text { Inclined planes }\end{array}$ & Proposition III & Proposition VII \\
\hline
\end{tabular}

Note that Galileo defined naturally accelerated motion, but demonstrated it only indirectly by means of the times-squared law ${ }^{1}$. In the Discorsi - contrary to the Horologium - there is no direct demonstration of naturally accelerated motion -only its indirect empirical consequences. On all other occasions, we can straightforwardly compare Galileo's and Huygens's inferential strategies (see the table). Galileo and Huygens proved these propositions each in a significantly different way. Huygens conceived of his demonstrations as being more clear («clarius») or better («optimè») than those originally given by Galileo in the Discorsi. Huygens however fully

1. As Huygens writes: «Quod Galileus principij sive hypothesis loco adsumsit, unde deinceps proportionem spatiorum quae aequalibus temporibus à cadente transeuntur demonstratum dedit.», Huygens, Christiaan. Oeuvres complètes de Christiaan Huygens. Vol. 17, Den Haag: M. Nijhoff; 1888-1950, p. 127 (emphasis added). 
acknowledged Galileo as his predecessor ${ }^{2}$. Huygens even claimed to annul his intention to write a book-length study of similar content like Galileo's Discorsi, since he did not want to compose the Iliad after Homer ${ }^{3}$.

Huygens's propositions on free fall are mentioned and presented in some level of detail by historians of science, but I think there is more we can learn from these propositions - especially on the methodological differences between Galileo and Huygens. Tacitly - or even explicitly ${ }^{4}$ - most historians of science presuppose that Huygens's propositions were only a rendering explicit of Galileo's implicit assumptions. This is true to some extent. However, behind Huygens's attempt to make Galileo's doctrine more explicit also lie profound methodological considerations. This is my main message. Correspondingly, I shall scrutinize the inferential steps made by Galileo and Huygens in their proofs concerning naturally accelerated motion. Several authors have only briefly commented on the difference between Galileo's and Huygens's mathematical approach on free fall - Christiane Vilain is a notable exception to this ${ }^{5}$. François De Gandt, for instance, notes that Huygens wished to demonstrate Galileo's law of free fall «without explicitly

2. Snelders, H.A.M. Christiaan Huygens' and Newton's theory of gravitation. Notes and Records of the Royal Society of London. 1989; 43 (2): 209-222, p. 219. Huygens explicitly refers to Galileo at several occasions: Blackwell, Richard J. Christiaan Huygens's the pendulum clock or geometrical demonstration concerning the motion of pendula as applied to clocks. Ames: The lowa State Press; 1986. p. 12, 40 and 42. For a general study of Huygens's intellectual biography John Bell's work: Bell, A.E. Christiaan Huygens and the development of science in the Seventeenth Century. London: Edward Arnold; 1947 is still valuable —it contains relevant algebraic transcriptions of some results of Huygens. Rienk Vermij's book is also of interest: Vermij, Rienk. Huygens: De mathematisering van de werkelijkheid. Diemen: Veen; 2004. Unfortunately, this work is only accessible for Dutch readers. Galileo's conception of relative motion is also tractable in Huygens's work, see: Pièces concernant la question du «movement absolu». In: Huygens, n. 1, vol. 17, p. 213-233, 222 and 232. For a careful analysis, see Mormino, Gianfranco. Penetralia motus. La fondazione relativistica della meccanica in Christiaan Huygens, con l'edizione del Codex Hugeniorum 7 A, La Nuova Italia: Firenze; 1993; Vilain, Christiane. Huygens et le mouvement relatif. Ph. D. dissertation. Université Paris 7; 1993.

3. Huygens, n. 1, vol. 11, p. 72-73. In an early manuscript (1659) on free fall, Huygens wrote down several propositions containing some of the material pertaining to the second part of the Horologium. See: Pièces correspondant à quelques parties de la pars secunda de «'Horologium Oscillatorium» de 1673, intitulée «De descensu gravium \& motu eorum in cycloïde». In: Huygens, n. 1, vol. 17, p. 125-137.

4. E.g., Yoder, Joella G. Unrolling Time. Christian Huygens and the mathematization of nature. New York: Cambridge University Press; 1988, p. 47

5. Vilain, Catherine. La loi galiléenne et la dynamique de Huygens. Revue d'histoire des mathématiques. 1996; 2: 95-117. 
supposing the dependence between time and the variation of velocity - he even believed it possible to derive demonstratively the fundamental property of heaviness, that at each equal interval of time there comes to be added an equal velocity» ${ }^{6}$. Michel Blay notes that Huygens's approach was «Euclidean in inspiration» and relied on «classical procedures of geometry and avoiding, in particular, recourse to infinite sums» ${ }^{7}$. Huygens aim was to present a «reconstruction of Galilean mechanics consistent with the requirements of rigor enforced by Euclidean geometry» ${ }^{8}$. His reconstruction eschewed Galileo's new but rather undeveloped mathematical techniques ${ }^{9}$. In similar fashion, Joella G. Yoder states that the axiomatic structure of geometry was the model of logical rigour for Huygens ${ }^{10}$. Huygens seemed to have a preference for classical-geometrical inferential strategies ${ }^{11}$. How can these be aptly characterized? H.J.M. Bos has briefly characterized Huygens's ma-

6. De Gandt, François. Force and Geometry in Newton's Principia, translated by Curtis Wilson. Princeton/New Jersey: Princeton University Press; 1995, p. 114. See also Vilain, n. 5, p. 117.

7. Blay, Michel. Reasoning with the infinite. From the closed world to the mathematical universe, translated by M.B. DeBevoise. Chicago: The University of Chicago Press; 1998, p. 27-28; see also, p. 37. This does not entail, of course, that Huygens never employed infinitesimals or infinite sums («infinita considerata multitudine») in his mathematical proofs. Yoder, n. 4, p. x. For Huygens's usage of limiting procedures, see especially Bos, H.J.M. Huygens and mathematics. In: Fletcher, K., ed. Proceedings of the International Conference TITAN, From discovery to encounter, 13-17 April 2004. Noordwijk: ESTEC; 2004, p. 67-80. In De Vi Centrifuga (1659), for instance, his treatment of centrifugal force is thoroughly infinitesimal. Idem for Huygens's derivation of the isochrony of the cycloid. Yoder, n. 4, p. 19-22 and 48-64. Aant Elzinga notes that Huygens allowed infinitesimals in the context of discovery. Elzinga, Aant. Review of Studies on Christian Huygens. The British Journal for the Philosophy of Science. 1983; 34 (3): 295-303 (35).

8. Blay, n. 7, p. 33; see also p. 36. For an overview of Huygens's mechanics, see Gabbey, Alan. Huygens and Mechanics. In: Bos, H. J. M. et al., eds. Studies on Christiaan Huygens. Invited Papers from the Symposium on the life and work of Christiaan Huygens. Amsterdam, 22-25 August 1979. Lisse: Swets and Zeitlinger; 1980, p. 166-199.

9. See Bos, H.J.M. Huygens and Mathematics. In: Bos et al. n. 8, p. 126-146, for a presentation of the development of Huygens's mathematics.

10. Yoder, n. 4, p. 172.

11. That is not to say that experiments were of lesser importance to Huygens. In his attempts to calculate the strength of surface gravity (measured by the distance of fall in one second), experiments were of utter importance, Yoder, n. 4, p. 9-43. In Huygens's natural philosophy, rational procedures were combined with experimental ones. As Huygens himself wrote: "Cum experientia ac ratione deprehendissem fune penduli vibrationes natura sua inaequales esse ita ut latiores angustioribus paulo plus temporis impendant, indeque erroris aliquid in horlogijs, praesertim quae elateris vi moventur neccesario acccidere, quaesivi quo pacto corrigere illam inaequalitatem possem». (quoted from a letter to Leopold de Medici, 28th November 1660), Huygens, n. 1, vol. 3, p. 197; emphasis added. 
thematical style as follows ${ }^{12}$. First, Huygens's classicism favoured strictly logical arguments based on reductio ad absurdum (as a means to avoid limit arguments, i.e. mathematical argument involving infinitesimals (see 3 and 4)). However, what Bos does not mention, one should carefully distinguish between reductio ad absurdum ${ }_{1}$ used to show the falsity of a hypothesis and reductio of absurdum ${ }_{2}$ used to establish the falsity of a claim's negation ${ }^{13}$ (and, hence, this method establishes the truth of a claim indirectly: from «not-not- $A »)$ we conclude: $\langle A »){ }^{14}$. This indirect usage of reduction, which is avoided by Euclid, is based on the excluded middle. Huygens used this type of reduction in cases where it was clear that there are only two logical options at hand. Secondly, Huygens actually thought geometrically, i.e. he focused on the relations in the figures and did not use formulas. Finally, Huygens also preferred axiomatisation.

Let me give an overview of this essay. In 2, I discuss Galileo's propositions on free fall that were mentioned in tree table; in 3, we shall look at the corresponding propositions in Huygens's treatment of free fall. The reader will notice that I shall begin by running through the proofs and then describe them on a meta-level. These analyses will be the input for our current endeavour: to compare the inferential strategies of Galileo and Huygens (4). I shall also further expand on Huygens's early mathematical classicism and point to its intimate connection with his preference for a more rigid methodology than hypothetico-deductivism, which Huygens endorsed later in his life. I shall also argue that Huygens's theoretical frame-work is more unified in two senses: (a) a broader domain of application is intended and (b) some inferential strategies are typically recurrent.

\section{Galileo's treatment of free fall}

My aim in this section is to analyse the propositions mentioned in the table in section 1. In this and the following section I will stay more descriptive. Theorem I, Proposition I is the mean-speed theorem or Mertonian rule which states that the «time in which any space is traversed by a body

12. Bos, n. 9, p. 131-132.

13. As Professor George E. Smith pointed out to me in private correspondence.

14. This procedure was, as is widely known, severely criticised by the intuitionists in mathematics (e.g., L.E.J. Brouwer). 
starting from rest and uniformly accelerated is equal to the time in which that same space would be traversed by the same body moving at a uniform speed whose value is the mean of the highest speed and the speed just before acceleration began» ${ }^{15}$. $A B$ represents the time in which the space $\mathrm{CD}$ is traversed (hence, the distance is the independent variable ${ }^{16}$ ) by a body, which starts to fall at rest from $C$ («Repraesentetur per existensionem $A B$ tempus in quo a mobile latione uniformiter accelerata ex quiete in $C$ conficiatur spatium $C D{ }^{17}$ ). See figure 1 . The horizontal, parallel lines represent what we would today call the instantaneous velocity (or more precisely, «crescentes velocitatis gradus post instans $A »{ }^{18}$ ). The triangle and

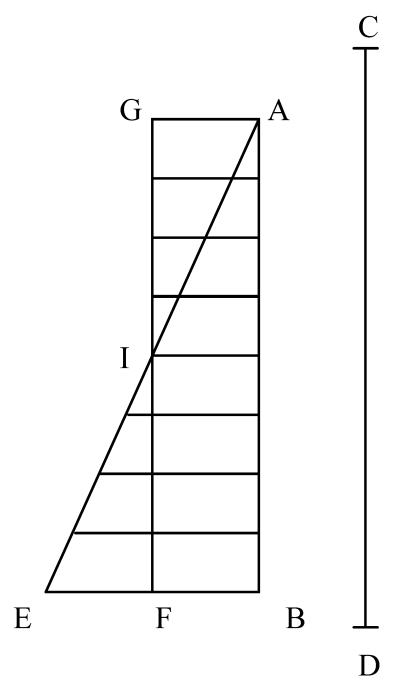

Figure 1.

15. Galilei, Galileo. Dialogues concerning two new sciences, translated by Henry Crew and Alfonso de Salvio. New York: Dover; 1954, p. 173.

16. Dijksterhuis remarks that Oresme used the traversed time as the independent variable. Dijksterhuis, E.J. De mechanisering van het wereldbeeld. Amsterdam: Meulenhoff; 1950. p. 257.

17. Galilei, Galileo. Le opere di Galileo Galilei. Nuova Ristampa della Edizione Nazionale. Edited by Antonio Favaro. Vol. 8, Florence: Barbèra; 1968. p. 208.

18. This notion was never explicitly defined by Galileo. Michel Blay writes on Galileo's notion of degree of velocity: «While to a certain extent it prefigured the concept of instantaneous velocity, it nonetheless remained subject to the Galilean way of conceiving motion, which regarded velocity as an 'intensive magnitude' increasing by successive additions of degrees». Blay, n. 7, p. 72. 
the rectangle represent the overall momentum acquired in a time-interval $\left[t, t^{\prime}\right]$ during uniformly accelerated motion (where the gradus velocitatis constantly increases) and during uniform motion (where the gradus velocitatis remains the same) respectively ${ }^{19}$.

The text proceeds as follows:

«Since each and every instant of time in the time-interval $A B$, from which points parallels drawn in and limited by the triangle AEB represent the increasing values of growing velocity, and since parallels contained within the rectangle represent the values of a speed which is not increasing, but constant, it appears, in like manner, that the momenta [momenta] assumed by the moving body may also be represented, in the case of the accelerated motion, by the increasing parallels of the triangle AEB, and, in the case of the uniform motion, by the parallels of the rectangle GB. For, what the momenta may lack in the first part of the accelerated motion (the deficiency of the momenta being represented by the parallels of the triangle AGI) is made up by the momenta represented by the parallels of the triangle IEF ${ }^{20}$.

The parallels of «instantaneous» speed are contained («comprehensae» or «contentae») in the triangle. The «aggregate» of all parallels contained in AEB equals the «aggregate» of the parallels contained in AGFB ${ }^{21}$. The degrees of speed that the uniform accelerated motion lack are made up during the second half ${ }^{22}$. The relation between uniform motion and uniformly accelerated motion is established by the equality between the surfaces which represent them. Galileo presupposed that the equality of the two infinite sets of moments of velocity establishes the equality of the corresponding overall speeds ${ }^{23}$. Galileo lacked adequate tools to deal with this thoroughly ${ }^{24}$. An important implicit premise is the mathematical assumption that an area is made up of indefinitely many lines. Let me sum up how Galileo represented uniformly accelerated motion:

19. Galilei, n. 15, p. 173.

20. Galilei, n. 15, p. 173-174.

21. Blay, n. 7, p. 74.

22. Dijksterhuis, E.J. Val en worp: Een bijdrage tot de geschiedenis van de mechanica van Aristoteles tot Newton. Groningen: P. Noordhoff; 1924, p. 257.

23. Damerow, Peter et al. Exploring the Limits of Preclassical Mechanics. New York: Springer; 1992. p. 230.

24. Clavelin, Maurice. La Philosophie Naturelle de Galilée. París: Armand Colin; 1968, p. 316. 
(1) $A B$, a line consisting of an infinite set of points, represents the time needed to traverse a distance $\mathrm{CD}$; every point corresponds to an instant of time; A represents the starting point $\left(t_{0}\right)$; $\mathrm{B}$ represents the end point $\left(t_{n}\right)$

(2) CD represents an arbitrary distance (hence, it is the independent variable)

(3) infinitesimal horizontal lines represents the (instantaneous) crescentes gradus velocitatis

(4) AEB represents the totality (totidem velocitatis momenta) of the increasing values of growing velocity (hence, the aggregate of the gradus velocitatis)

(5) AGFB represents the totality of the constant values of speed (hence the aggregate of the constant speeds)

The aim is to show that, in equal times, a uniform motion with $1 / 2$ overall momentum of an accelerated motion will traverse the same distance (neglecting at that point the question if such motions really exist). This proposition will be used as an inference-ticket or proxy in the following

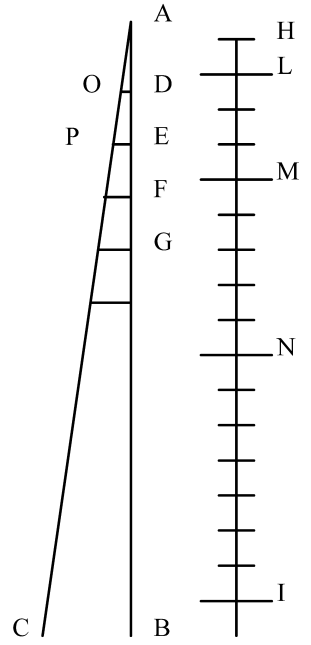

Figure 2. proposition, i.e. uniformly accelerated motion will be reduced to the already solved problem of uniform motion.

Theorem II, Proposition II is the squaredtime law which states that the «spaces described by a body falling from rest with a uniformly accelerated motion are to each other as the squares of the time-intervals employed in traversing these distances» ${ }^{25}$. The units of time («fluxus temporis») are represented on $\mathrm{AB}$; the distances through which a body falls with a uniform acceleration starting from rest are represented by HI. See figure 2. Time AD corresponds to length $\mathrm{HL}, \mathrm{AE}$ to $\mathrm{HM}, \mathrm{AF}$ to $\mathrm{HN}$ and AG to HI. $\mathrm{AC}$ is constructed at an arbitrary angle on $\mathrm{AB}$ («quemcunque angulum»). OD and PE represent the maximum speed at $\mathrm{D}$ and $\mathrm{E}$. 
The proof proceeds as follows ${ }^{26}$. From the mean-speed theorem it follows that the distances HM and HL are the same as those that would be traversed during $\mathrm{AE}$ and $\mathrm{AD}$ by a uniform motion with half the speeds of those by which DO and EP are represented. Since ratio AE is to AD as $1 / 2 \mathrm{EP}$ is to $1 / 2 \mathrm{DO}$ or as EP to DO, the velocities are to each other as the time-intervals $(v \sim t)$. Galileo replaced the accelerated motions by uniform motions. From Theorem IV, Proposition IV (in the section on uniform motion) which states that «if two particles are carried with uniform motion, but each with a different speed, the distances covered by them during unequal intervals of time bear to each other the compound ratio of the speeds and time intervals», Galileo concludes: $x \sim(v \times t)^{27}$. Hence, the ratio of the spaces traversed is the same as the squared ratio of the time-intervals (hence: $x \sim t^{2}$ ). Again, Galileo used information about a simple situation (uniform motion) to a less simple situation (accelerated motion). Galileo then argued from his famous inclined plane experiments that the natural phenomena agree to this proposition. Galileo seems, at least in the presentational or expositional part of his theory, not to spend much attention on the details of the experiments. Let me sum up:

(1) $\mathrm{AB}$, a line consisting of an infinite set of points, represents the time needed to traverse a distance $\mathrm{HI}$; every point corresponds to an instant of time; A represents the starting point $\left(t_{0}\right)$; B represents the end point $\left(t_{n}\right)$; time-intervals $\mathrm{AD}, \mathrm{AE}, \mathrm{AF}$ and $\mathrm{AG}$ correspond to distances HL, HM, HN and HI

(2) OD and PE represent the gradus velocitatis at instants of time D and $\mathrm{E}$

(3) HL, HM, HN, HI represent the distances traversed in time-intervals $\mathrm{AD}, \mathrm{AE}, \mathrm{AF}, \mathrm{AG}$

The proof for the odd-number rule is stated as a corollary to the times-squared rule (see figure 3). AO represents the time measured from the initial point $\mathrm{A}$. The horizontal lines $\mathrm{BC}$, IF, OP represent the velocity at the corresponding points C, I, O. As Galileo assumed, the velocity is proportional to the time elapsed. By the mean speed theorem we know

26. See also Wisan, Winifred L. The new science of motion. A study of Galileo's De Motu Locali. Archive for History of Exact Sciences. 1974; 13 (2-3): 103-306 (286-288).

27. Gailei, n. 15, p. 157. 


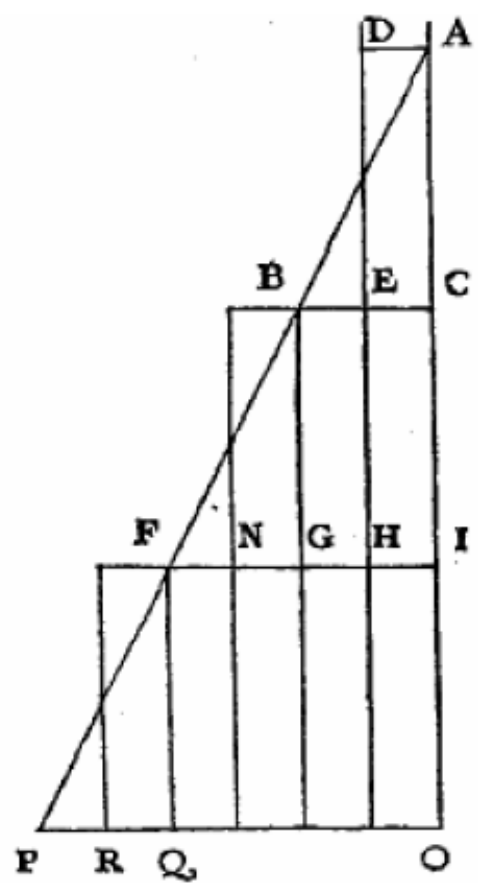

Figure 3. Source: Galilei, n. 17, p. 211.

that a body in free fall will arrive at $C$ with speed $B C$ in equal times as a body moving with a uniform motion with half of the speed of $\mathrm{BC}$. If a body would continue to move uniformly at speed $\mathrm{BC}$ it would in time $\mathrm{CI}$ traverse twice the distance traversed in AC. A body in free fall will during equal increments of time acquire equal increments of speed (by the definition of naturally accelerated motion). It follows that the velocity $\mathrm{BC}$ during the next time-interval will be increased by an amount represented the triangle BFG which is equal to the triangle $A B C$. Since the area $\mathrm{ABC}$ equals $\mathrm{DAEC}$ and BCFI equals three times DAEC, in time-interval $\mathrm{CI}$ three times the distance of that in time $\mathrm{AC}$ will be described. In time interval OI, velocity IF will be increased by an amount represented by the triangle FPQ and the body will have traversed a distance five times that of AC. Hence, it is evident «by simple computation that a moving body starting from rest and acquiring velocity at a rate proportional to the time, will during equal interval of time traverse distances which are related to each other as the odd numbers beginning with unity, $1,3,5{ }^{28}$. The structure of this proof is ${ }^{29}$ :

(1) By the mean speed theorem, we may use a uniform motion («rectangles») to gather information on the distance traversed by an accelerated motion («triangles»).

28. Galilei, n. 15, p. 177.

29. In modern terminology the same result can be obtained more easily as follows: $s=1 / 2 \mathrm{~g}$. (t $2^{2}$ $\left.\mathrm{t}^{2}{ }^{2}\right)=\mathrm{g} / 2(\mathrm{t} 2+\mathrm{t} 1) .(\mathrm{t} 2-\mathrm{t} 1)$. If $\mathrm{t} 2-\mathrm{t} 1=1$ (e.g. one second), then $\mathrm{s}=\mathrm{g} / 2(\mathrm{t} 2+\mathrm{t} 1)$, where $\mathrm{t} 2+\mathrm{t} 1$ is always an odd number because it is the sum of two consecutive numbers. 
(2) By elementary geometry these equalities follow: $\mathrm{ABC}=\mathrm{DAEC}$, $\mathrm{BCFI}=3 \times$ DAEC, FIPO $=5 \times$ DAEC, $\ldots$ etc.

(3) Hence, we conclude that the distances traversed will be to each other as $1,3,5, \ldots$ etc.

After the scholium to this proposition, a dialogue was inserted a year after the publication of the Discorsi (Galileo was blind at that time) by Viviani at the suggestion of Galileo «for the better establishment on logical and experimental grounds, of the principle which we have above considered ${ }^{30}$. The lemma states that the ratio between the momentum of a body $\mathrm{G}$ along the vertical FC is to the momentum of the same body along the inclined plane FA as the inverse of that of the aforementioned lengths (hence: $\left.v_{1} / v_{2}=x_{2} / x_{1}\right)^{31}$. See figure 4 . The impelling force acting on a body in descent («limpeto del descendere») is equal to the resistance or least force sufficient to hold it at rest (ibid.). To measure this force body $\mathrm{G}$ is connected to body $\mathrm{H}$ with a cord passing over $\mathrm{F}$. We notice that, in order to hold $\mathrm{G}$ at rest, $\mathrm{H}$ must have a weight smaller in the same ratio as CF is smaller than FA (transcribed: $W(\mathrm{G}) / W(\mathrm{H})=\mathrm{FA} / \mathrm{FC}$ or $W_{1} / W_{2}=$ $\left.x_{1} / x_{2}\right)$. Galileo then writes:

«For if we consider the motion of the body G, from A to F, in the triangle AFC to be made up of a horizontal component AC and a vertical component $\mathrm{CF}$, and remember that this body experiences no resistance to motion along the horizontal (because by such a motion the body neither gains nor loses distance from the common center of heavy things) it follows that resistance is met only in consequence of the body rising through the vertical distance CF. Since then the body G in moving from A to F offers resistance only in so far as it rises through the vertical distance $\mathrm{CF}$, while the other body $\mathrm{H}$ must fall vertically through the entire distance FA, and since this ratio is maintained whether the motion be large or small, the two bodies being inextensibly connected, we are able to assert positively that, in case of equilibrium (bodies at rest) the momenta, the velocities, or their tendency to motion, i.e. the spaces which would be traversed by them in equal times, must be in the inverse ratio of their weights. This is what has been demonstrated in every case of mechanical motion» ${ }^{32}$.

30. Galilei, n. 15, p. 180.

31. Galilei, n. 15, p. 182.

32. Galilei, Galileo. Dialogues concerning two new sciences, translated by Henry Crew and Alfonso de Salvio. New York: Dover; 1954, p. 182-183 [emphasis added]. The translators point out 


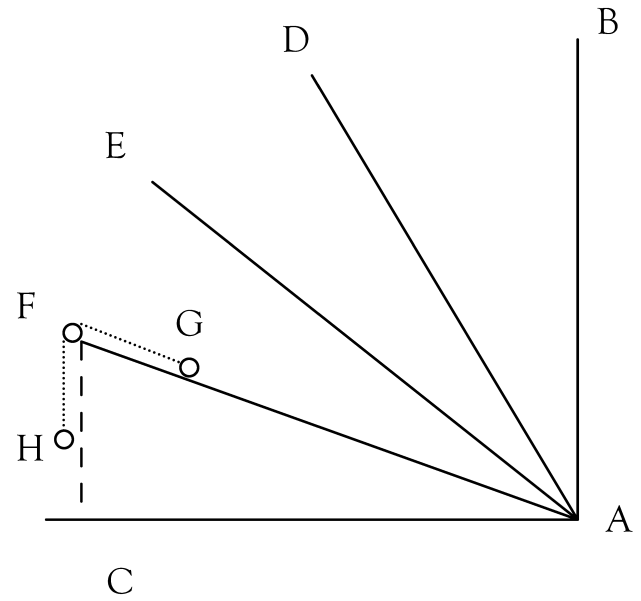

Figure 4.

Hence, in equilibrium, the velocities are to each other as the inverse ratio of the weights $\left(v_{1} / v_{2}=W_{2} / W_{1}\right)$. Notice that this involves the introduction of virtual velocities. This result combined with the previous ratio $\left(W_{1} / W_{2}\right.$ $\left.=x_{1} / x_{2}\right)$ leads to the result: $v_{1} / v_{2}=x_{2} / x_{1}$, which was to be demonstrated. This theoretical principle is used to interpret the empirical finding that, in order to hold $G$ at rest, $H$ must have a weight smaller (than $G$ ) in the same ratio as CF is smaller than FA. Hence, the momenta are as $I(\mathrm{G}) / I(\mathrm{H})$ $=\mathrm{FA} / \mathrm{FC}$.

The theorem (which I shall refer to as the «equal-height-equal-momentum theorem») states that the (final) speeds at different angles along an inclined plane at equal heights are the same. From the construction, it is given that: $A D$ is the third proportional to $A B$ and $A C(A B / A D=A D /$ $A C)^{33}$. See figure 5. From the lemma, it follows that the impetus along $A C$ is to that along $\mathrm{AB}$ as $\mathrm{AB}$ is to $\mathrm{AC}$.

Hence, the impetus along $\mathrm{AC}$ is to that along $\mathrm{AD}$ as $\mathrm{AC}$ is to $\mathrm{AD}$. Therefore, the body will traverse $\mathrm{AD}$ in the same time as $\mathrm{AC}$, because the momenta are in the same ratio as these distances. We also know from the definition of accelerated motion that the speed at B is to the speed at D as

that this principle is «a near approach» of the principle of virtual work formulated by Jean Bernoulli in 1717 (p. 183n).

33. Galilei, n. 15, p. 184. 
the time required to traverse $A B$ is to that to traverse $\mathrm{AD}$ and that the time to traverse $A B$ is to that to traverse $\mathrm{AD}$ as $\mathrm{AC}$ and $\mathrm{AD}$ (Corollary 2 to Theorem II, Proposition II). Hence, the speeds are equal ${ }^{34}$. This theorem uses the lemma to infer the initial information $(I(\mathrm{AB}) / I(\mathrm{AC})=\mathrm{AC} / \mathrm{AB})$, which is a physical interpretation of the inclined plane. This information is transformed by means of Corollary II to Proposition II and the given information that $\mathrm{AD}$ is the third proportional between $A B$ and $A C$.

Theorem III, Proposition III states that if «one and the same body, starting from rest, falls along an inclined plane and also along a vertical, each having the same height, the times of descent will be to each other as the lengths of the inclined plane and the vertical» ${ }^{35}$. Let a body fall along AC and long the vertical $\mathrm{AB}$. Both motions take place from the same height: $A B$. See figure 6.

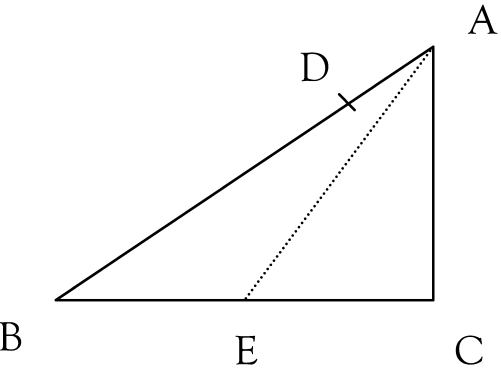

Figure 5 .

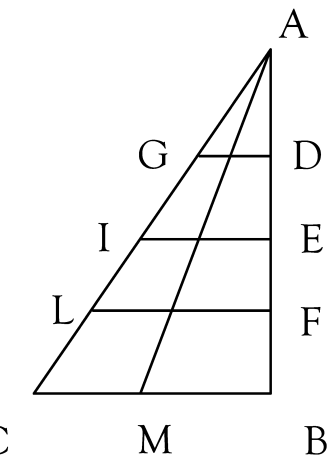

Figure 6 .

34. Transcribed we get the following. From the lemma we get: /(AC)//(AB) $=A B / A C$. («/» stands for impetus; these relations are purely proportional). From what is given we know that: $A C / A B$ $=\mathrm{AD} / \mathrm{AC}$. From the given third proportionality it follows that: $/(\mathrm{AC}) / /(\mathrm{AD})=\mathrm{AC} / \mathrm{AD}$. From this it follows that: $t(A D)=t(A C)$ («t» stands for the time necessary to traverse a given distance). From the definition of naturally accelerated motion it follows: $/(B) / /(D)=t(A B) / t(A D)$. From Corollary II to Theorem II, Proposition II, it follows that: $t(A B) / t(A D)=A C / A D$. Hence, $/(B)=/(C)$. I prefer to remain close to the original text in order to respect «the linguistic character» of Galileo's proofs. Palmieri, Paolo. Mental models in Galileo's early mathematization of nature. Studies in History and Philosophy of Science. 2003; 34: 229-264, p. 230. I have included these transcriptions in order to facilitate the comprehension of the modern reader. According to Dijksterhuis, this proof is Aristotle's dynamics applied to the comparison of movements in equal times. Dijksterhuis, n. 22, p. 264.

35. Galilei, n. 15, p. 185. 
The final speeds («gradus velocitatum in terminis») at $\mathrm{C}$ and $\mathrm{B}$ are equal (this follows from the equal-height-equal-momentum theorem). If the speeds are equal then the ratio of the times of descent will be to the ratio of the distances themselves. Therefore, the time of descent along $\mathrm{AC}$ is to that along $\mathrm{AB}$ as the length of the plane $\mathrm{AC}$ is the vertical $\mathrm{AB}^{36}$.

\section{Huygens's treatment of free fall ${ }^{37}$}

Huygens's treatment of free fall can be found in the pars secunda (De descendu Gravium \& motu eorum in Cycloïde) of the Horologium oscillatorium which was first published in $1673^{38}$. I shall especially focus on Propositions I-VIII, in which Huygens gives some new proofs of the core propositions of Galilean mechanics ${ }^{39}$. In the introductory text to the Horologium Oscillatorium, Huygens stated that he used «some new demonstrations to stabilize and expand further the doctrine of the great Galileo concerning the falling of heavy bodies», i.e. to create and develop a more unified theoretical framework ${ }^{40}$. Huygens began the second part with the following three hypotheses:

«I. If there were no gravity, and if the air did not impede the motion of bodies, then any body will continue its given motion with uniform velocity in a straight line.

II. By the action of gravity, whatever its sources ${ }^{41}$, it happens that bodies are moved by a motion composed both of a uniform motion in one direction or another and of a motion downward due to gravity.

III. These two motions can be considered separately, with neither being impeded by the other ${ }^{42}$ ».

\footnotetext{
36. If $/(B)=/(C)$, then $t(A B) / t(A C)=A B / A C$.

37. I will use Richard H. Blackwell's translation of the Horologium Oscillatorium. Blackwell, Richard H. De Pendulum Clock or Geometrical Demonstration Concerning the Motion of Pendula as Applied to Clocks. Ames: The lowa State University Press; 1986). Where relevant, I will refer to the Latin edition from Huygens's Oeuvres Complètes.

38. Blackwell, n. 37, p. 33-72.

39. Blackwell, n. 37, p. 33-46.

40. Blackwell, n. 37, p. 12

41. In the Horologium, Huygens wished to remain agnostic concerning the mechanism which produces gravity. De Gandt, n. 6, p. 115.

42. Blackwell, n. 37, p. 33.
} 
The first hypothesis amounts to what we call the law of inertia. The second and third hypotheses concerns the principle of composition of motion in free fall and the independence of these component motions. If we accept these hypotheses, "we can discover the cause and the laws of acceleration of heavy falling bodies», as Huygens stated $^{43}$. This is done in the following propositions, which we shall now discuss in more detail.

We begin with Proposition I, which states the uniformly accelerated character of free fall:

«In equal times equal amounts of velocity are added to a falling body, and in equal times the distances crossed by a body falling from rest are successively increased by an equal amount» ${ }^{4}$.

The proof for this proposition goes as follows ${ }^{45}$. Suppose there is a body at rest at A (see figure 7). In the first unit of time ${ }^{46}$, it falls through distance $A B$ and at $B$ it will have acquired a velocity by which it next would cross BD with a uniform velocity (equal to the velocity acquired at B by free fall) in the second unit of time. In the second unit of time, the motion is composed ${ }^{47}$ of a uniform motion (by hypothesis 2) by which alone it would traverse $\mathrm{BD}$ and a motion caused by gravity which makes the body fall through distance AB. Hence, if we add distance $\mathrm{DE}$ (equal to $\mathrm{AB}$ ) to $\mathrm{BD}$, we obtain the distance traversed (BE) in the second unit of time. The velocity acquired at $E$ at the end of the second unit of time is double the velocity acquired at B in the first unit of time. In the third unit of time, the distance EG

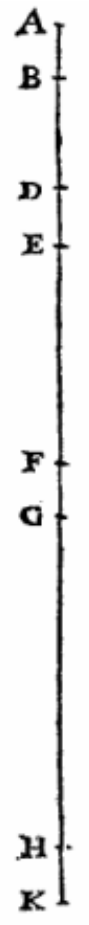

Figure 7. Source: Huygens, Christiaan. Horologium oscillatorium seu de motu pendulorum ad horologia aptato demonstrationes geometricae. Paris: F. Muguet; 1673, p. 27.

\footnotetext{
43. Blackwell, n. 37, p. 34.

44. Blackwell, n. 37, p. 34

45. Blackwell, n. 37, p. 35.

46. Huygens used the expression «primo tempore» here. Huygens, n. 1, vol. 18, p. 127. He consistently used «tempus» to denote the units of time.

47. «Feretur vero motu composito ex aequabili [motu, i.e. uniform motion] (...) \& ex motu gravium cadente (...)». Huygens, n. 1, vol. 18, p. 127.
} 
will be traversed. At $\mathrm{G}$, the total velocity is found by adding the uniform component, which is equal to twice the velocity acquired at $\mathrm{B}$, and the gravitational component («vis gravitatis»), equal to the speed acquired at $\mathrm{B}^{48}$. Hence, the velocity acquired at the third unit of time is three times the velocity acquired at the first unit of time. And so forth for all following (finite) units of time. Hence, in each amount of time equal increments of speed are made ${ }^{49}$. The argument goes as follows ${ }^{50}$ :

$$
\begin{aligned}
& \mathrm{t}_{1}: \mathrm{x}_{1}=\mathrm{AB}, \mathrm{v}_{1} \\
& \mathrm{t}_{2}: \mathrm{x}_{2}=\mathrm{BE}, \mathrm{v}_{2}=2 \cdot \mathrm{v}_{1}\left(=\text { uniform component } \mathrm{v}_{1}+\text { accelerated component } \mathrm{v}_{1}\right) \\
& \mathrm{t}_{3}: \mathrm{x}_{3}=\mathrm{EG}, \mathrm{v}_{3}=3 \cdot \mathrm{v}_{1}\left(=\text { uniform component } \mathrm{v}_{2}+\text { accelerated component } \mathrm{v}_{1}\right) \\
& {[\ldots]}
\end{aligned}
$$

Huygens's demonstration is essentially a step-by-step decomposition of downward motion.

Proposition II states a provisional version of the mean-distance theorem:

«The distance crossed in a certain time by a body beginning to fall from rest is one-half the distance which it would cross in an equal time with a uniform motion whose velocity is equal to the velocity acquired ${ }^{51}$ at the last moment of the fall» ${ }^{52}$.

Assuming the previous figure, Huygens argues that distance $\mathrm{BD}$ is twice $\mathrm{AB}$. In the first four units of time the distances $\mathrm{AB}, \mathrm{BE}, \mathrm{EG}$, and $\mathrm{GK}$ are traversed. Distances $A E$ and $E K$ are to each other as $A B$ to BE. From this it follows that $\mathrm{KE} / \mathrm{EA}=\mathrm{EB} / \mathrm{AB}=\mathrm{DA} / \mathrm{AB}^{53}$. From Proposition $\mathrm{I}$, it follows that

48. Hence, it is also implicitly supposed that fall occurs in an empty and homogeneous space, where the action of gravity is constant. See Vilain, Christiane. Espace et dynamique chez Christiaan Huygens. De Zeventiende Eeuw: Cultuur in de Nederlanden in interdisciplinair perspectief. 1996; 12 (1): 235-243 (p. 241). The assumption that gravity acts constant is false, see section 4.

49. Huygens writes «velocitates per aequalia tempora aequaliter augeri». Huygens, n. 1, vol. 18, p. 129.

50. $t_{x}$ stands for the $x$ th unit of time, $x_{x}$ for the distance traversed after the $x$ th unit of time, and $v_{x}$ for the velocity acquired at the xth unit of time. The general format of Huygens solution is: $x_{n}=1 / 2 t_{n} \cdot\left(t_{n}-1\right) . B D+t_{n}$. AB. Vilain, n. 48, p. 113.

51. The Latin text states «cum velocitate quam acquisivit». Huygens, n. 1, vol.18, p. 129.

52. Blackwell, n. 37, p. 36.

53. Huygens, of course, formulates these geometrical relations verbatim. 
$\mathrm{KE}=2 \cdot \mathrm{AB}+5 \cdot \mathrm{BD} . \mathrm{We}$ also know that $\mathrm{EA}=2 \cdot \mathrm{AB}+\mathrm{BD}$. Hence: $\mathrm{KE}-\mathrm{EA}=$ 4.BD. From this: $\mathrm{DB} / \mathrm{BA}=4 . \mathrm{DB} / \mathrm{EA}$. Therefore, $\mathrm{EA}$ will be four times $\mathrm{BA}$, which equals $2 . \mathrm{AB}+\mathrm{BD}, \mathrm{BD}=2 \mathrm{AB}$. This proposition presupposes a proportion between the distances traversed by a falling body in equal times, a supposition which Huygens later shows how to avoid in Proposition $\mathrm{V}^{54}$. Let us run again through the proof ${ }^{55}$ :

(1) $\mathrm{AE} / \mathrm{EK}=\mathrm{AB} / \mathrm{BE}$ (by construction)

(2) $\mathrm{KE} / \mathrm{EA}=\mathrm{EB} / \mathrm{AB}=\mathrm{DA} / \mathrm{AB}$ (from (1))

(3) $\mathrm{KE}=2 . \mathrm{AB}+5 . \mathrm{BD}$ (by construction; see figure 7 )

(4) $\mathrm{EA}=2 . \mathrm{AB}+\mathrm{BD}$ (by construction; see figure 7)

(5) $\mathrm{KE}-\mathrm{EA}=4 . \mathrm{BD}((3) \&(4))$

(6) $\mathrm{DB} / \mathrm{BA}=4 . \mathrm{DB} / \mathrm{EA}$ (by construction we know that $\mathrm{EA}=4 . \mathrm{BA}$ )

(7) $\mathrm{EA}=4 . \mathrm{BA}(6)$

(8) $\mathrm{BD}=2 \cdot \mathrm{AB}((4) \&(7))^{56}$

Proposition III contains a formulation of the times-squared law:

«If two distances are crossed by a falling body in any times, each of which is measured from the beginning of the fall, these distances are related to each other as the duplicate ratio of these times, or as the squares of the times, or as the squares of the velocities acquired at the end of these times» ${ }^{57}$.

From Proposition II it follows that distance $\mathrm{BD}$ is twice $\mathrm{AB}$, distance $B E$ is triple $A B$, distance $E G$ five times $A B$, distance $G K$ seven times $A B$, and so on for the remaining distances. Hence, the distances traversed at time units $1,2,3,4, \ldots$ etc. increase according to the progression of odd numbers starting $a b$ unitate: $1,3,5,7, \ldots$ etc. If «the times are assumed

\footnotetext{
54. Blackwell, n. 37, p. 40

55. René Dugas wrote: «Nous citons ces démonstrations, parce qu'elles diffèrent quant au fond de celles de Galilée. Elles font en effet in intervenir, à chaque instant, la composition de la vitesse acquise et de la chute nouvelle du grave.» Dugas, René. Histoire de la mécanique. Neufchâtel: Editions du Griffon; 1950, p. 176.

56. For the reader's convenience: $D B / B A=4 \cdot D B / E A$. Since $D B / B A=4 \cdot D B /(2 \cdot A B+B D), 2 \cdot D B \cdot A B+D B^{2}$ $=4 \cdot D B \cdot B A$. Thus: $D^{2}=4 \cdot D B \cdot B A-2 \cdot D B \cdot A B=2 \cdot D B \cdot B A$. From this, we obtain: $2 \cdot A B=D B^{2} / D B=$ DB.

57. Blackwell, n. 37, p. 36.
} 
to be commensurable» ${ }^{58}$, the distances are related to each other as the squared ratio of the corresponding times ${ }^{59}$. Next, shows that this result «is easy to extent to incommensurable times» (ibid.):

(1) Let us suppose: $\mathrm{E} / \mathrm{F}>\mathrm{AB}^{2} / \mathrm{CD}^{2}$ - see figure 8 . In this case: $\mathrm{AB}^{2} /$ $\mathrm{CG}^{2}=\mathrm{E} / \mathrm{F}$, where $\mathrm{CG}$ is smaller than $\mathrm{CD}$. From CD subtract $\mathrm{DH}$, which is smaller than DG, the excess of CD over CG (ibid., p. 37). Let this be done in such a way that $\mathrm{HC}$ is commensurable to $\mathrm{AB}$. Then obviously: $\mathrm{CH}>\mathrm{CG}$. The squares of the times $\mathrm{AB}$ and $\mathrm{CH}$ will be as the distance $\mathrm{E}$ stands to the distance it would traverse in the time $\mathrm{CH}$. The distance $\mathrm{F}$ traversed in time $\mathrm{CD}$ is larger than this distance. From this, we have: $\mathrm{E} / \mathrm{F}<\mathrm{AB}^{2} / \mathrm{CH}^{2}$. Hence, $\mathrm{AB}^{2} / \mathrm{CG}^{2}<\mathrm{AB}^{2} / \mathrm{CH}^{2}$. From this it follows that $\mathrm{CH}^{2}<\mathrm{CG}^{2}$ (and thus: $\mathrm{CH}<$ $\mathrm{CG}$ ), which yields an inconsistency. Therefore, we reject the hypothesis.

(2) In a similar fashion we can derive an inconsistency from the hypothesis that $\mathrm{E} / \mathrm{F}<\mathrm{AB}^{2} / \mathrm{CD}^{2}$. Huygens concludes this proposition with the words:

«Finally, since the velocities acquired at the end of the times AB and CD are related to each other in the same way as these times, it is obvious that $E$ is related to $F$ by the same ratio as the squares of the times $A B$ and $C D$ in which they are crossed ${ }^{60}$.

The structure of this proof is:

(1) $\mathrm{BD}=2 . \mathrm{AB}$ (Proposition II)

(2) $\mathrm{BE}=3 . \mathrm{AB}$ (by idem)

(3) $\mathrm{EG}=5 . \mathrm{AB}$ (by idem)

58. Blackwell, n. 37, p. 37. The Encyclopaedia of Mathematics states that two magnitudes of the same kind are commensurable, if they have a common measure (i.e. a magnitude of the same kind contained in an integral numbers of times in both of them). If two magnitudes are commensurable, then their ratio is a rational number (if not, then it is an irrational number). See Hazewinkel, Michiel, ed. Encyclopaedia of Mathematics. Vol. 1, Dordrecht/Boston/London: Kluwer; 1995, p. 714.

59. Huygens notes: «And since any sum of these numbers [i.e., 1, 3, 5, 7, ... etc.], taken consecutively, makes a square whose side equals the number of numbers taken (for example, if the first three are added, they make nine; if four sixteen), it follows from this that the distances crossed by a falling body, each of which is taken from the beginning of the fall, are related to each other as the duplicate ratio of the times during which the fall occurs, [...]» Blackwell, n. 37, p. 37.

60. Blackwell, n. 37, p. 38. 
(4) $\mathrm{GK}=7 \cdot \mathrm{AB}$ (by idem)

$[\ldots]$

If we assume that the times are commensurable, it follows that: $\mathrm{x}_{1} / \mathrm{x}_{2}=\mathrm{t}_{1}{ }^{2} / \mathrm{t}_{2}{ }^{2}$

That the claim holds when the times are incommensurable can be by the following reductio ad absurdum:

(1) $\mathrm{E} / \mathrm{F}>\mathrm{AB}^{2} / \mathrm{CD}^{2}$ (ex hypothesi) ${ }^{61}$

(2) $\mathrm{AB}^{2} / \mathrm{CG}^{2}=\mathrm{E} / \mathrm{F}$, where $\mathrm{CG}<\mathrm{CD}$ (by (1))

(3) $\mathrm{DG}=\mathrm{CD}-\mathrm{CG}$, where $\mathrm{HC}$ is commensurable to $\mathrm{AB}$ (by (2))

(4) $\mathrm{CH}>\mathrm{CG}$ (by (3))

(5) $\mathrm{E} / \mathrm{F}<\mathrm{AB}^{2} / \mathrm{CH}^{2}$ (by (2) \& (4))

(6) $\mathrm{AB}^{2} / \mathrm{CG}^{2}<\mathrm{AB}^{2} / \mathrm{CH}^{2}$ (by (2) \& (5))

(7) $\mathrm{CH}^{2}<\mathrm{CG}^{2}$ (from which it follows: $\mathrm{CH}<\mathrm{CG}$ ) (by $(6))$

(8) Hence, we reject $\mathrm{E} / \mathrm{F}>\mathrm{AB}^{2} / \mathrm{CD}^{2}$

(9) Finally: $\mathrm{E} / \mathrm{F}=\mathrm{AB}^{2} / \mathrm{CD}^{2}\left(\mathrm{x}_{1} / \mathrm{x}_{2}=\mathrm{t}_{1}{ }^{2} / \mathrm{t}_{2}{ }^{2}\right)$

Proposition IV goes as follows:

«If a heavy body begins to move upwards with the same velocity acquired at the end of a descent, then in equal parts of time it will cross the same distances upwards as it did downwards, and it will rise to the same height from which it descended. Also in equal parts of time it will lose equal amounts of velocity ${ }^{62}$.

This amounts to proving that in as many equal times as the distances $\mathrm{AB}, \mathrm{BE}, \mathrm{EG}$, and GK are traversed by a body which falls from $A$, the same distances $\mathrm{KG}, \mathrm{GE}, \mathrm{EB}$, and $\mathrm{BA}$ are traversed successively by the
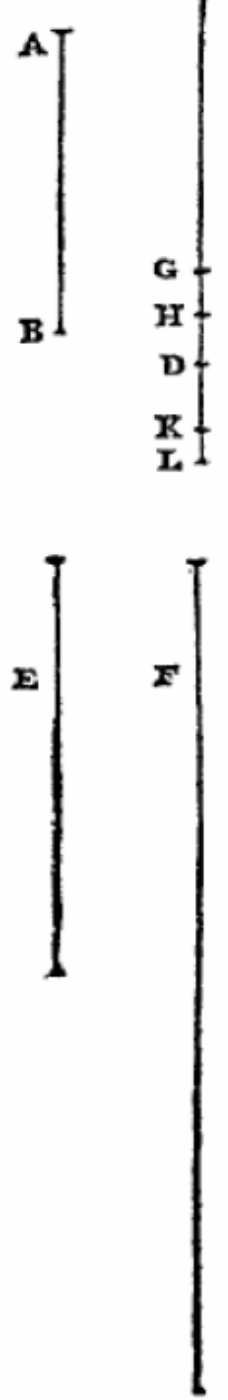

Figure 8. Source: Huygens, 1673, p. 26.

61. The proof can easily be constructed for the hypothesis: $E / F<A B^{2} / C D^{2}$.

62. Blackwell, n. 37, p. 38. 
same body when it moves upwards beginning with the velocity acquired at $\mathrm{K}$ (after free fall from A) - see figure 8 . Huygens notes that «for the sake of brevity each velocity ${ }^{63}$ will be successively designated by the length of the distance crossed by a body in uniform motion with that velocity in one part of time» ${ }^{64}$. When a body arrives at K, it has acquired velocity KF (= $\mathrm{GH}+\mathrm{BD}$ ). If this velocity is directed upwards it will traverse the distance $\mathrm{KF}$ in one unit of time. If we take into account the "action of gravity», this distance will be decreased by FG (= AB) ${ }^{65}$. The body rises only to G. At G the remaining velocity is $\mathrm{HG}(=\mathrm{GD})$. In the second unit, of time the body would traverse GD, from which we need to subtract ED, which equals the action of gravity. At $\mathrm{E}$, the remaining velocity is $\mathrm{FE}(=\mathrm{GD}-\mathrm{BD})$. If that body moves further upwards (in the third unit of time), by its uniform motion distance EA would normally be traversed in one unit of time. From EA we still need to subtract the action of gravity, i.e. AB. The result is that the body will rise to $B$. In the fourth unit of time, the body finally reaches $A$ and no velocity is left. The body does not move higher. From this it follows that «the body rises to the same height from which it fell, and that each distance crossed in equal times of descent is equally measured off in as many equal times of ascent» ${ }^{66}$. The structure of Proposition IV is:

Given: at $\mathrm{K}$ falling body's velocity is $\mathrm{KF}(=\mathrm{GH}+\mathrm{BD})$ $\mathrm{t}_{1}$ :

when velocity $\mathrm{KF}(=\mathrm{GH}+\mathrm{BD})$ is directed upwards: the body rises to $\mathrm{G}$ at $\mathrm{G}$ the remaining velocity is $\mathrm{HG}(=\mathrm{GD})$

$\mathrm{t}_{2}$ :

when velocity $\mathrm{HG}$ is directed upwards: the body rises to $\mathrm{E}$ at $\mathrm{E}$ the remaining velocity is $\mathrm{FE}(=\mathrm{GD}-\mathrm{BD})$ $\mathrm{t}_{3}$ :

when velocity $\mathrm{FE}$ is directed upwards: the body rises to $\mathrm{B}$ at $\mathrm{B}$ the remaining velocity is $\mathrm{AB}(=\mathrm{BD}-\mathrm{AB})$ $\mathrm{t}_{4}$ :

63. Westfall notes that Huygens's diagrams, contrary to Galileo's, presented the velocities and only incidentally the paths; velocity emerged more clearly than in Galileo's mechanics as a physical quantity. Westfall, Richard. Force in Newton's physics: The science of dynamics in the seventeenth century. Dordrecht/Boston/London: Elsevier; 1971, p. 153.

64. Blackwell, n. 37, p. 38.

65. Blackwell, n. 37, p. 38.

66. Blackwell, n. 37, p. 49 . 
when velocity $A B$ is directed upwards: the body rises to $A$ at $A$ remaining velocity is zero $(A B-A B)$

Notice that Huygens proves this proposition by illustrating it with a case with four units of time. Obviously, the demonstration applies to any finite set of subsequent units of time.

Proposition V contains a new proof of the mean-distance theorem, which Galileo gave «in a less perfect form» ${ }^{67}$ :

«The distance crossed in a certain time by a body which begins its fall from rest is half the distance which it would cross in an equal time with a uniform motion having the velocity acquired at the last moment of the fall ${ }^{68}$ ».

Let $\mathrm{AH}$ represent the total time of fall and AC, CE, EG, ... etc. the equal parts of time (see figure 9). In $\mathrm{AH}$ a moving body traverses a distance whose quantity is represented («designetur») by the plane P. HL represents the terminal velocity acquired at the end of the fall («celeritatem in fine casus acquisitam»). AHLM represents the distance crossed in time AH with velocity HL. We need to show that $\mathrm{P}$ is $1 / 2$ AHML or that P equals AHL. We prove this by reductio ad absurdum ${ }^{69}$. If $\mathrm{P}$ is not equal to $1 / 2 \mathrm{MH}$ or AHL, then it is either smaller or greater. Let us examine both cases. Keep in mind that the distances are represented by means of surfaces.

(1) Assume that P is smaller than AHL. Let AH be divided by a number of equal parts $\mathrm{AC}, \mathrm{CE}, \mathrm{EG}, \ldots$ etc. Then construct the circumscribed figure that is composed of rectangles whose altitudes equal each part of the division of $\mathrm{AH}$, namely the rectangles $\mathrm{BC}, \mathrm{DE}, \mathrm{FG}, \ldots$ etc. Also construct within the

67. Blackwell, n. 37, p. 40. Huygens notes that the proof of the mean-distance theorem in Proposition II was based on the supposition that there is a proportion between the distances traversed by falling bodies. Huygens remarks: «This indeed must be so because of the nature of the way that things are related to each other, and if this is denied, it must be admitted that it is useless to search for a proportion between these distances». Blackwell, n. 37, p. 40. The mean-distance theorem can also be proved without this supposition by using Galileo's method ("Galilei methodum sequendo»). Huygens concludes: «Hence it will be a worthwhile effort to write down here more accurately the demonstration which he gave in a less perfect form». Blackwell, n. 37, p. 40.

68. Blackwell, n. 37, p. 40.

69. Michel Blay notes that: «Huygens' strategy, though it did involve the proportionality of speed to time, was feasible only to the extent that it immediately substituted distances for time. Huygens' reasoning was, in a manner of speaking, static». Blay, n. 7, p. 36. 

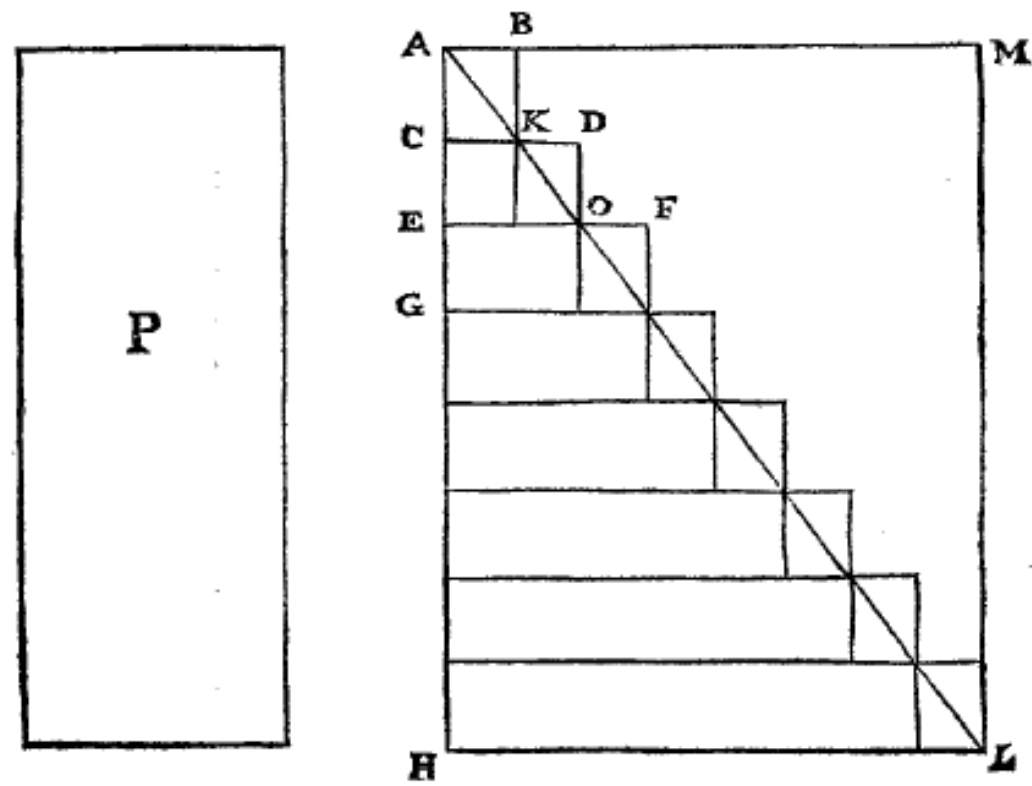

Figure 9. Source: Huygens, 1673, p. 29.

triangle an inscribed figure composed of rectangles of the same altitude, namely the rectangles KE, OG, ... etc. All this is done so that the excess (equal to the lowest rectangle with base HL) of the circumscribed figure over the inscribed figure is less than the excess of AHL over P. From this, it follows that the excess of AHL over the inscribed figure will be less than its excess over P. In this case, the inscribed figure is larger than P. Since, by Proposition I, we know that the velocities of falling bodies are proportional to the times of fall, $\mathrm{CK}$ is the velocity acquired at the end of the first unit of time, for $\mathrm{AH} / \mathrm{AC}=\mathrm{HL} / \mathrm{CK}$. Similarly, $\mathrm{EO}$ is the velocity acquired at the end of the second unit of time. In the first instant of time, a distance greater than zero is traversed. In the second unit of time, a distance greater than KE is traversed, since during CE distance KE would be traversed by a uniform motion with the velocity $\mathrm{CK}$, which is equal to the uniform component to which the action of gravity still needs to be added. Similarly, during EG a distance greater than OG is traversed. And so on for all successive times. Hence, the total distance crossed by an accelerated motion will be greater than the inscribed figure. That distance was $a b$ initio assumed to be equal 
to the plane P. Hence, the inscribed figure will be smaller than distance P. Thus, the plane P is not smaller than AHL. Our initial hypothesis leads to an inconsistency and needs to be rejected.

(2) Assume that P is larger than AHL. The excess of the circumscribed figure over the inscribed figure is less than the excess of P over AHL. Hence, the circumscribed figure will be less than plane $\mathrm{P}$. In the first unit of time $\mathrm{AC}$, the distance crossed by an accelerated motion is less than $\mathrm{BC}$, because that distance would be crossed in the same time with the uniform velocity CK which the body acquires only at the end of time CE. Similarly, during $\mathrm{CE}$ a distance less than DE is traversed (because it would be crossed in the same time CE with the uniform velocity $E O$ which it acquires only at the end of time CE). And so on for all successive times. Hence, the whole distance crossed by an accelerated motion will be less than the circumscribed figure. But that distance was ab initio assumed to be equal to the plane P. Hence, the inscribed figure will be smaller than plane P. Thus, the plane $\mathrm{P}$ is not larger than AHL. Our initial hypothesis leads to an inconsistency and needs to be rejected.

Since we have shown that plane P is not larger and not smaller than AHL, it follows that both must be equal. The structure of this proof is the following:

Let us assume that in $\mathrm{t}(\mathrm{AH})$ a distance is traversed represented by the plane $\mathrm{P}$, that $\mathrm{HL}$ represents the terminal velocity at the end of fall along $\mathrm{AH}$, and that AHLM represents the distance crossed in time AH with uniform velocity $\mathrm{HL}$. We want to prove: $\mathrm{P}=1 / 2 \mathrm{AHML}=\mathrm{AHL}$.

Suppose $\mathrm{P} \neq 1 / 2$ AHML $\neq \mathrm{AHL}$, then two options $((\alpha) \&(\beta))$ are open:

(a) $\mathrm{P}<\mathrm{AHL}$ (ex hypothesi)

(1) (area circumscribed figure - area inscribed figure) $<$ (AHL - P) (by construction)

(2) (AHL - area inscribed figure) < (AHL - P) (by (1))

(3) area inscribed figure $>\mathrm{P}$ (by (2))

(4) $t_{1}$ : a distance greater than zero is traversed (by Proposition I)

$t_{2}$ : a distance greater than KE is traversed (by idem)

$\mathrm{t}_{3}$ : a distance greater than OG is traversed (by idem)

$[\ldots]$ 
$\mathrm{t}_{\mathrm{n}}$ : a distance greater than the greatest rectangle of the inscribed figure is traversed (by idem) ${ }^{70}$

(5) Hence: whole distance crossed by an accelerated motion $(=\mathrm{P})>$ inscribed figure (by [4])

(6) Hence: area inscribed figure $<\mathrm{P}$ (in contradiction with (3))

(7) Finally, we reject $\mathrm{P}<\mathrm{AHL}$

( $\beta)$ P $>$ AHL

(1) (area circumscribed figure - area inscribed figure) $<(P-A H L)$ (by construction)

(2) area circumscribed figure $<\mathrm{P}$ (by (1))

(4) $t_{1}$ : a distance smaller than BC is traversed (by Proposition I)

$\mathrm{t}_{2}$ : a distance smaller than DE is traversed (by idem)

$[\ldots]$

$\mathrm{t}_{\mathrm{n}}$ : a distance smaller than the greatest rectangle of the circumscribed figure is traversed (by idem)

(5) Hence: whole distance crossed by an accelerated motion $(=\mathrm{P})<$ circumscribed figure (by (4))

(6) Hence: area circumscribed figure $>\mathrm{P}$ (in contradiction with (2))

(7) Finally, we reject $\mathrm{P}>\mathrm{AHL}$

Since both options are untenable, we conclude $\mathrm{P}=1 \frac{1}{2}$ AHML $=$ AHL.

Proposition VI — of which «Galileo asked that we accept is as in a sense being self-evident» ${ }^{71}$ (ibid., p. 42) - can easily be derived:

«The velocities acquired ${ }^{72}$ by bodies falling through variably inclined planes are equal if the elevations of the planes are equal» ${ }^{73}$.

70. There is no mathematical induction here. Huygens constructed this proof with a finite amount of steps precisely in order to evade Galileo's precarious assumption of infinitesimals.

71. The Latin text reads «ut quodammodo per se manifestam, Galileus postulavit». Huygens, n. 1, vol. 18, p. 141. Even Galileo's later addition of the scholium in the edition of 1654 could not convince Huygens. Blackwell, n. 37, p. 42-43.

72. In a manuscript from 1659 - Huygens' annis mirabilis - Huygens used the Galilean term «gradus velocitatis». Huygens, n. 1, vol. 17, p. 131.

73. Blackwell, n. 37, p. 43. 


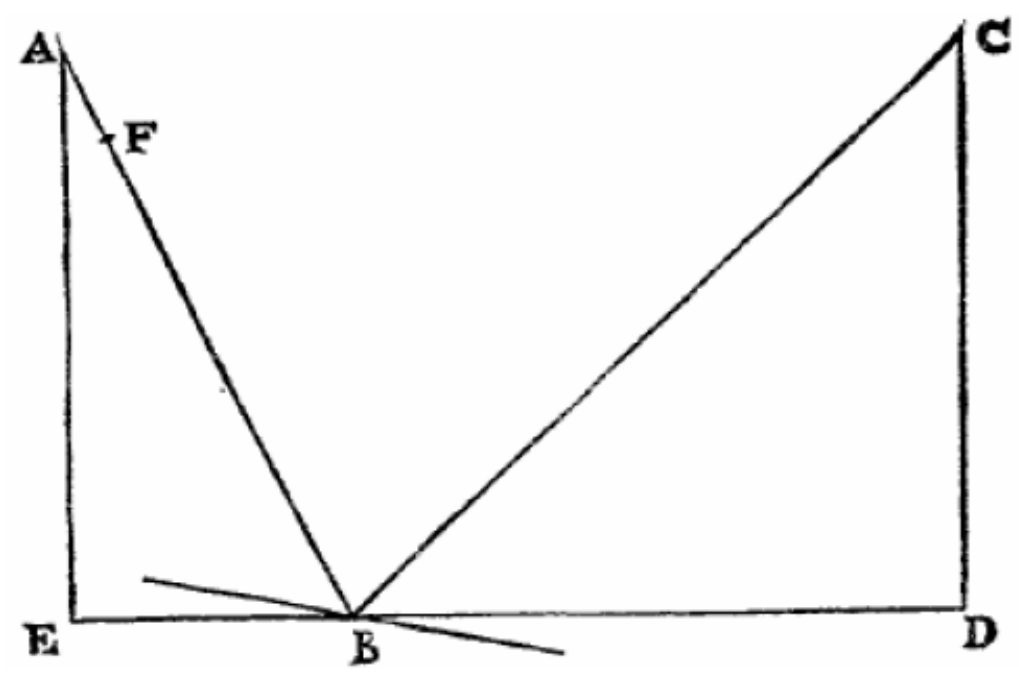

Figure 10. Source: Huygens, 1673, p. 32.

Let a body roll down from the inclined planes $\mathrm{AB}$ and $\mathrm{CB}$, the heights of which $\mathrm{AE}$ and $\mathrm{CD}$ are equal - see figure 10. In both cases «the same degree of velocity will be acquired» («eundem gradum velocitatis acquisiturum») ${ }^{74}$. If along an inclined plane $\mathrm{CB}$, less velocity than along $\mathrm{AB}$ were to be acquired, the velocity acquired along $\mathrm{CB}$ would be the same as on an arbitrary FB which has a height less than AE. From Proposition $\mathrm{IV}$, it follows that the velocity acquired along $\mathrm{CB}$ is required to make the body ascend through the whole of $\mathrm{BC}$. If we then suppose that the fall along $\mathrm{FB}$ is continued through $\mathrm{BC}$, «which it could do by reflection in the oblique direction» ${ }^{75}$, it would move up to $\mathrm{C}$, i.e. up to a point higher than the place from which it fell. This assumption is absurd - since it violates Torricelli's principle ${ }^{76}$, which states that the centre of gravity cannot raise above itself ${ }^{77}$. Huygens finally notes that:

\footnotetext{
74. Blackwell, n. 37, p. 43.

75. Blackwell, n. 37, p. 43.

76. See Loria, Gino; Vassura, Giuseppe, eds. Opere di Evangelista Torricelli. Vol 2, Faenza: Stabilimento Tipo-litografico G. Montanari; 1919, p. 105, for Torricelli's own formulation. I am indebted to Professor George E. Smith for this reference.

77. See Huygens, n. 1, vol. 17, p. 132, 4n; Blackwell, n. 37, p. 108-109.
} 
«From this there properly follows the demonstration of another of Galileo's theorems on which are built all the other theorems which he presented concerning motions along inclined planes ${ }^{78}$.

The structure of the proof is the following reductio ad absurdum inference:

(1) suppose $\mathrm{v}(\mathrm{AB}) \neq \mathrm{v}(\mathrm{CB})$, thus: $\mathrm{v}(\mathrm{AB})>\mathrm{v}(\mathrm{CB})$ (ex hypothesi $^{79}$

(2) $\mathrm{v}(\mathrm{CB})=\mathrm{v}(\mathrm{FB})$ (by (1) and construction)

(3) $\mathrm{v}(\mathrm{CB})=\mathrm{v}(\mathrm{BC})$ (by Proposition IV)

(4) $\mathrm{v}(\mathrm{FB})$ would continue to $\mathrm{C}$ (by (2), (3) \& Proposition IV), which is absurd

(5) Hence: $\mathrm{v}(\mathrm{AB})=\mathrm{v}(\mathrm{CB})($ reductio ad absurdum (1)-(4))

Proposition VII proves that:

«The times of descent on variably inclined planes whose elevations are equal are related to each other as the lengths of the planes» ${ }^{80}$.

From Proposition II, it follows that the time required to fall along AC is equal to the time needed for a uniform motion with half the velocity acquired at $\mathrm{AC}^{81}$ to go through $\mathrm{AC}$ - see figure $11^{82}$. Idem for AD. From Proposition VI, it follows that these uniform velocities are equal. Hence, the times of these uniform motions are to each other as AC to AD. From this we obtain that the times of fall through $\mathrm{AC}$ is to $\mathrm{AD}$ as $\mathrm{AC}$ to $\mathrm{AD}$.

(1) $\mathrm{t}_{\mathrm{a}}(\mathrm{AC})=\mathrm{t}_{1 / 2 \mathrm{u}}($ AC) (by Proposition II)

(2) $t_{a}(A D)=t_{1 / 2 u}(A D)$ (by Proposition II)

(3) $\mathrm{v}_{\mathrm{u}}\left(\right.$ AC) $=\mathrm{v}_{\mathrm{u}}($ AD) (by (1)-(2) and Proposition VI)

(4) $t_{u}(A C) / t_{u}(A D)=A C / A D$ (definition uniform motion)

(5) $\mathrm{t}_{\mathrm{a}}(\mathrm{AC}) / \mathrm{t}_{\mathrm{a}}(\mathrm{AD})=\mathrm{AC} / \mathrm{AD}($ by $(3) \&(4))$

\footnotetext{
78. Blackwell, n. 37, p. 43.

79. The proof can be constructed similarly for the reverse direction $(v(A B)<v(C B))$.

80. Blackwell, n. 37, p. 44.

81. I will denote this somewhat unluckily as: «ta(AC) $=\mathrm{t} 1 / 2 \mathrm{u}(\mathrm{AC}) »$.

82. Huygens wrote on this proposition: «Galilei optimè hoc modo demonstratur quem et Galileus indicat». Huygens, n. 1, vol. 17, p. 132. Huygens's demonstration does not require Galileo's construction with a mean proportional.
} 


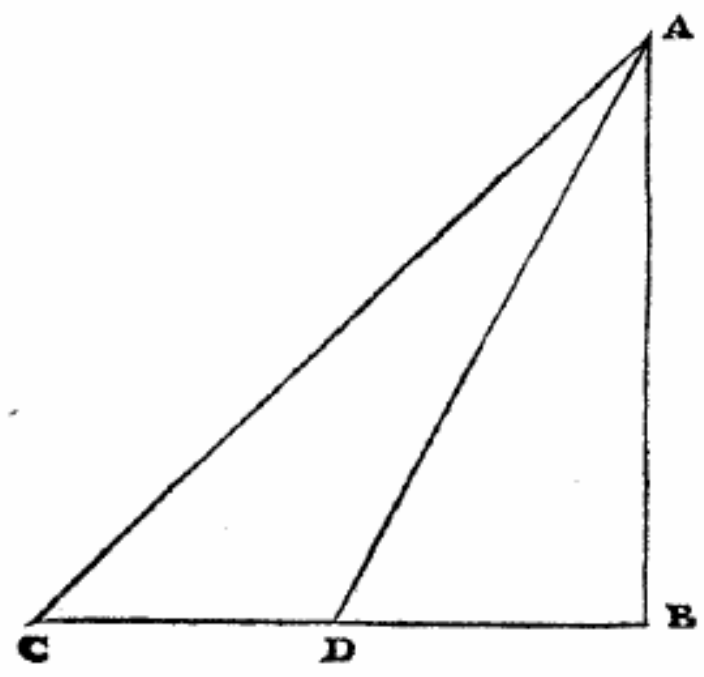

Figure 11. Source: Huygens, 1673, p. 33.

To conclude, I add an analysis of Proposition VIII which states that:

«If from the same height a body descends by a continuous motion through any number of contiguous planes having any inclinations whatsoever; it will always acquire at the end the same velocity; namely, a velocity equal to that which would be acquired by falling perpendicularly from the same height ${ }^{83}$ ».

Along fall from the contiguous planes $\mathrm{AB}, \mathrm{BC}$, and $\mathrm{CD}$, a body will acquire the same velocity at $\mathrm{D}$ which it would have at $\mathrm{F}$ by falling along the perpendicular EF (see figure 12). Extend $C B$ and $C D$ as indicated on the figure. By Proposition VI, it follows that a body when falling through $A B$ will acquire at $B$ the same velocity as through GB. Similarly, at $C$ a body falling through $\mathrm{GC}$ will have acquired the same velocity as through $\mathrm{EC}$, and at $\mathrm{D}$ a body will have acquired the same velocity through fall along ED as through EF. Hence, the speed acquired along AD is equal to that acquired along EF. Since each curve can be considered as an infinitude of straight 


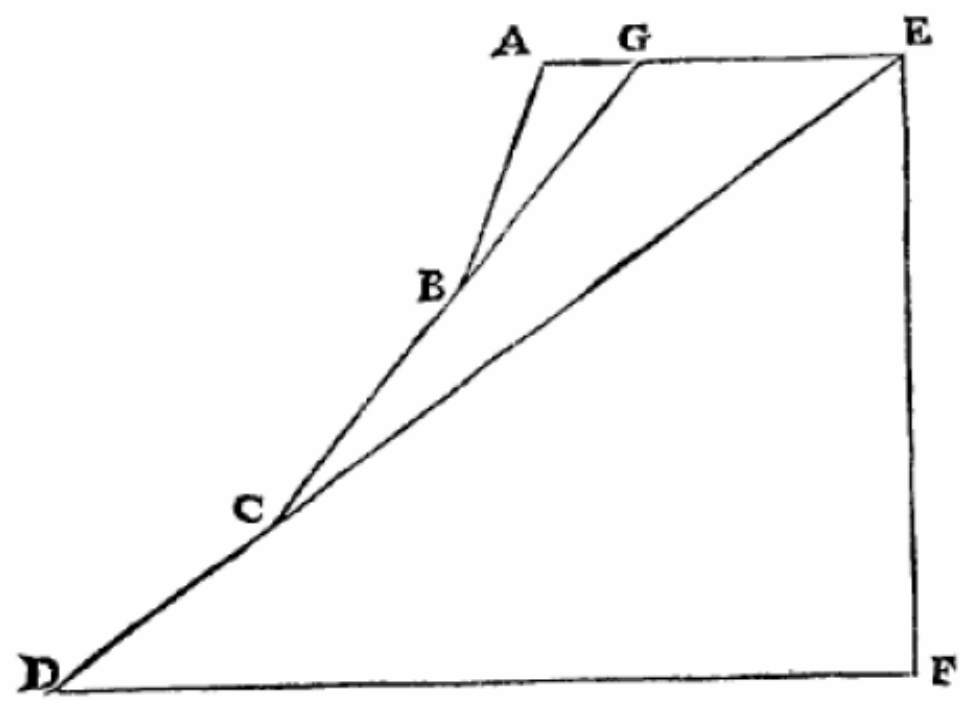

Figure 12. Source: Huygens, 1673, p. 34.

lines ${ }^{84}$, this proposition can also be applied to circles and all curves ${ }^{85}$. The structure of the proof is:

(1) $\mathrm{v}(\mathrm{AB})=\mathrm{v}(\mathrm{GB})$ (by Proposition VI)

(2) $\mathrm{v}(\mathrm{GC})=\mathrm{v}(\mathrm{EC})$ (by idem)

(3) $\mathrm{v}(\mathrm{ED})=\mathrm{v}(\mathrm{EF})$ (by idem)

(4) $\mathrm{v}(\mathrm{AD})=\mathrm{v}(\mathrm{EF})($ by $(3) \&$ idem $)$

84. This is one of the few occasions where Huygens introduces a limiting procedure. Huygens makes a similar move in Proposition XXI. Huygens, n. 1, p. 59. Proposition XXI states: «Let a body descend by a continuous motion through any number of contiguous planes, and later let it descend from the same height through another series of an equal number of contiguous planes. Let the letter series be constructed in such a way that each plane corresponds in height to another plane in the first series, but let the planes in the second series have a larger inclination than those in the first series. Now I say that the time of descent through the less inclined planes will be less than the time of descent through the more inclined planes.». Huygens, n. 1, p. 58. The proof boils down to determining in both cases the total times of descent by adding the times needed to traverse each individual plane. After this proof, Huygens invites us to consider curves as being composed of an infinitude of inclined planes. Huygens, n. 1, pp. 58-59. In Proposition XXI, Huygens needs to assume that a cycloid consists of infinitely small tangents.

85. Yoder, n. 4, p. 47. 


\section{Comparing Galileo and Huygens}

In this final section, I show how the analyses in the two foregoing sections confirm the theses stated in the introduction. The explanatory ideal of the early-Huygens was axiomatic-deductive. Correspondingly, his classicist proof-style attempted to leave no assumption unjustified and to deductively demonstrate every step. In Galileo's work, by contrast, several unjustified presuppositions are embedded in the propositions. Let us look, for instance, at the presuppositions underlying Galileo's Proposition I and II. The relation between uniform motion and uniformly accelerated motion is established by the equality between the surfaces which represent them. Galileo needs to presuppose that the equality of the two infinite sets of moments of velocity establishes the equality of the corresponding terminal velocities ${ }^{86}$. Galileo, however, lacked the adequate mathematical tools to deal with this ${ }^{87}$. That a surface was composed of or could be formulated exactly by an infinitude of lines was a daring statement. Galileo's propositions are essentially based on these geo-infinitesimal properties. Huygens tried to avoid any reference to infinitesimals and he typically «decomposed» motion in a finite set of time-intervals. Let us look at some further examples. While in Theorem I Galileo simply $a b$ initio assumed that during the first interval of time the motion simply is uniformly accelerated, prima facie Huygens did not make that presupposition. Christiane Vilain notes:

«It is only upon decomposing the motion of the second time interval into an inertial motion and a motion equal to that of the first time interval that Huygens recognizes that the speed of the falling body must have doubled from the end of the first time interval to the end of the second. Given that the time has doubled too, the speed must have grown in proportion to the time ${ }^{88}$ ».

86. Damerow et al., n. 23, p. 230.

87. Clavelin, n. 24, p. 316.

88. Vilain, Christiane. Christiaan Huygens's Galilean Mechanics, in: Palmerino, C.R.; Thijssen, J.M.M.H., eds. The Reception of the Galilean Science of Motion in Seventeenth-Century Europe. Dordrecht/Boston/London: Boston Studies in the Philosophy of Science; 2004. p. 185-198 (186). E.J. Dijksterhuis noted that «het werkelijk eerst den schijn heeft, alsof de quadratenwet op geheel legitieme wijze te voorschijn komt». Dijksterhuis, n. 16, p. 404. I am indebted to Professor George E. Smith for pointing to this place in Dijksterhuis' book. 
However, Huygens recognition that gravity («which clearly is the same in the second unit of time as in the first» ${ }^{89}$ ) is uniform is false since the acceleration of gravity near the surface of the Earth is not uniform but varies according to the inverse-square law. Here, Huygens's attempt failed. In Proposition III Huygens's assumption that the times are commensurable is neatly demonstrated with a reductio ad absurdum. In Pars Secunda of the Horologium, Huygens indeed consistently used his classical geometrical approach (epitomized by reductiones and stepby-step decomposition (see following paragraph)). He rarely mentioned experiments in Propositions I-VIII. Huygens preferred the logical mode of exposition of classical geometry. This logical a priori style is very different from some of his later hypothetico-deductive statements in the Traité de la lumière (1690) ${ }^{90}$ :

«On verra de ces sortes de demonstrations, qui ne produisent pas une certitude aussi grande que celle de Geometrie, \& qui mesme en different beaucoup, puisque au lieu que les Geometres prouvent leurs Propositions par des Principes certain $\mathcal{E}$ incontestables, icy les Principes se verifient par les conclusions qu'on tire; la nature de ces choses ne souffrant pas cela se fasse autrement. Il est possible toutefois d'y arriver à un dergré de vraisemblance, qui bien souvent ne cede guere à une evidence entiere». Huygens, 1888-1950, vol. 19, p. 454 (emphasis added).

Vilain has noted that Huygens's later hypothetico-deductive stance was quite different from his work in the Horologium ${ }^{91}$. This essay further confirms this. In the Horologium, Huygens intended to proceed like the

89. Blackwell, n. 37, p. 35.

90. This attitude can also be found earlier statements. Huygens famously wrote: «Qu'en matière de physique il n'y a pas de demonstrations certaines, et qu'on ne peut scavoir les causes que par les effects en faisant des suppositions fondees sur quelques experiences ou phenomenes connus, et essayant ensuite si d'autres effects s'accordent avec ces mesmes suppositions. (...) Cependant ce manque de demonstration dans les choses de physique ne dois pas nous faire conclure que tout y est egalement incertain, mais il faut avoir egard au degrè de vraisemblance qu'on trouve selon les nombres des experiences qui conspirent a nous confirmer dans ce que nous avons supposé». Quoted from a letter to Pierre Perrault, 1673. Huygens, n. 1, vol. 7, p. 300 (emphasis added).

91. Vilain, n. 48, p. 296-300. A study of how Huygens changed his mind on these matters would be a worthwhile project. Hanc marginem non caperetur. 
geometers ${ }^{92}$ he described in the foregoing quote: he wished to prove his propositions by certain and indubitable principles. The early Huygens preferred providing the logical grounds for accepting a theoretical statement above the agreement of hypotheses with the relevant data. Galileo seemed to be satisfied with the latter:

«Let us then, for the present, take this as a postulate, the absolute truth of which will be established when we find that the inferences from it correspond to agree perfectly with experiment» (Galileo, 1954, p. 172).

In his treatment of free fall, Huygens wanted to establish a geometrically rigid science, in which all presuppositions are clearly stated and proved directly.

Huygens's classicism entailed a strong preference for rigorous mathematical inferential steps, particularly reductio ad absurdum and decomposition. In the case of the former, we demonstrate that the contrary of that which we seek to prove is false and therefore that what we seek is true. In the case of the latter, we decompose a situation into a finite and arbitrary number of steps and afterwards we show that each other relevant situation can be similarly decomposed into a finite amount of steps. Reductio ad absurdum is used in Propositions III, V, and VI. Huygens strongly believed in the argumentative power of reductio ad absurdum. Decomposition is used in Propositions I and IV. He typically decomposed motions into their uniform and uniformly accelerated components. In these propositions, he used a finite set that can be extended to all other finite sets. Obviously, this is a way of avoiding limiting arguments.

In correspondence to his adherence to the ideal of mathematical classicism, Huygens favoured a theoretical frame-work that is more unified than Galileo's. Huygens noted that from Proposition VI «follows the demonstration of another of Galileo's theorems on which are built all the other theorems which he presented concerning motions along inclined planes» ${ }^{93}$. In other words, Huygens spelled out and justified the unifying principle for the motions of all bodies in free fall along inclined paths. Contrary to Galileo, Huygens immediately extends (in Proposition VIII) the time-length pro-

92. Huygens claimed that nature itself invites us to be geometers. Huygens, Christiaan. The celestial Worlds discoverd. London: Frank \& Cass; 1969, p. 84.

93. Blackwell, n. 37, p. 44. 
portionality for motion along vertical and inclined planes to motions along all curves. Huygens's propositions, therefore, applied to a greater domain, while Galileo's proposition had a more restricted scope ${ }^{94}$.

\section{Acknowledgments}

The author wishes to thank Fabien Chareix, Gianfranco Mormino. Eric Schliesser, Joella G. Yoder, and Christiane Vilain for their advice and guidance when working on this paper. He is indebted to Rienk Vermij for several comments and specially to George E. Smith, of whom he had the absolute honour to receive a cornucopia of useful feedback, remarks and criticisms. This essay is dedicated to the incomparable Mr. Smith.

94. The following studies have helped the author a lot: Schliesser, Eric; Smith, George E. Huygens's 1688 Report to the Directors of the Dutch East Indian Company on the measurement of longitude at sea and the evidence it offered against universal gravity. Archive for History of Exact Sciences (forthcoming). Chareix, Fabien. La pésanteur dans l'univers méchanique de Christiaan Huygens. De Zeventiende Eeuw 1996; 12 (1): 244-252. Chareix, Fabien. Expérience et raison, la science chez Huygens (1629-1695). Revue d'Histoire des Sciences. 2003; 56 (1): $79-112$. 